\title{
Skull Metastasis Extending to the Superior Sagittal Sinus: An Unfamiliar Presentation of Papillary Thyroid Carcinoma
}

\author{
Abu Baker Sheikh ${ }^{1}$, Aisha Akhtar ${ }^{2}$, Usman Tariq ${ }^{3}$, Abdul Ahad E. Sheikh ${ }^{4}$, Fasih Sami Siddiqui ${ }^{4}$, Marvi \\ M. Bukhari ${ }^{5}$ \\ 1. Internal Medicine, University of New Mexico, Albuquerque, USA 2. Department of Surgery, Texas Tech University \\ Health Sciences Center, Lubbock, USA 3. Research Assistant, Yale University School of Medicine, New Haven, USA 4. \\ Student, Shifa College Of Medicine, Islamabad, PAK 5. Internal Medicine, Shifa College Of Medicine, Islamabad, PAK
}

Corresponding author: Abdul Ahad E. Sheikh, ahad_esn@hotmail.com

\section{Abstract}

Thyroid cancer is the most common endocrine cancer in the world, with a rising global incidence over the last three decades. Papillary thyroid cancer (PTC) is the most common type of thyroid neoplasia, accounting for $74 \%-80 \%$ of all cases. Skull metastasis from a differentiated thyroid malignancy is a rare occurrence, while a subsequent dural involvement is even more inimitable. As such, a clinician requires a high degree of clinical suspicion and resultant radiographic evidence in order to make the diagnosis. Here we present the case of a 54-year-old male patient who presented with a pathological fracture of his right humerus, a midline frontal bone swelling and an asymptomatic neck mass. Further workup revealed follicular variant papillary thyroid carcinoma (FV-PTC) with distant metastasis to the calvarium. The conventional therapy for metastatic PTC includes a total thyroidectomy, removal of resectable metastatic lesions and a supplementation with radioactive iodine (RAI) and/or external beam radiation at the sites of the metastases. This case and our literature review illustrate that skull metastases should be considered in the clinical course of PTC so that appropriate management can be started.

Received 05/29/2018

Review began 05/29/2018 Review ended 05/31/2018 Published 06/05/2018

\section{() Copyright 2018}

Sheikh et al. This is an open access article distributed under the terms of the Creative Commons Attribution License CC-BY 3.0., which permits unrestricted use, distribution, and reproduction in any medium, provided the original author and source are credited.
Categories: Pathology, General Surgery, Oncology

Keywords: humerus fracture, superior sagittal sinus invasion, papillary thyroid carcinoma, metastasis

\section{Introduction And Background}

Thyroid cancer is the most prevalent endocrinal malignancy in the world, with an incidence that continues to rise worldwide in the last three decades. Papillary thyroid cancer (PTC) is the most common variant of this malignancy and accounts for $74 \%-80 \%$ of all its presentations. PTC usually has a slow progression and is associated with a regional spread to the cervical lymph nodes. It carries a favorable outcome, except in the presence of a metastatic disease process [1]. Distant metastases (DM) occur in approximately $10 \%$ of the patients with a PTC, with the lung and bone being the most commonly perpetrated sites $[2,3]$. While the follicular variant of a papillary carcinoma has a greater propensity for bony metastasis, distant metastasis from a primary PTC to the calvarium and a subsequent encroachment of the brain is a very rare clinical predicament. We present a case akin to this metastatic distribution that presented as a large soft tissue mass on the head.

\section{Review}

\section{Case presentation}

A 54-year-old male with multiple comorbidities including hypertension, hyperlipidemia, type II diabetes mellitus and stage II chronic kidney disease, presented to our facility with complaints of a gradually enlarging frontal bone mass for the last one month, as well as progressive right arm pain which exacerbated with movement, following a malunion fracture of his right humerus. He also had a painless neck swelling for the last two years which went unreported, owing to a lack of any associated symptoms such as dyspnea, dysphagia or hoarseness.

Initial assessment suggested that he was in good physical health with a heart rate (HR) of 82/minute, respiratory rate (RR) of $18 /$ minute with $97 \%$ oxygen saturation, a temperature of $98.4^{\circ} \mathrm{F}$ and blood pressure (BP) of 112/75 mm Hg. He was found to be well oriented with intact responses to an extensive cranial nerve exam. The swelling in the left frontal region of the head was easily discernable. It measured $6 \mathrm{~cm} \mathrm{x} 7 \mathrm{~cm}$, soft and warm to the touch with a normal overlying skin but a palpable erosion of the underlying bone. A concomitant examination of his neck divulged a large left thyroid mass which measured $8 \mathrm{~cm} \times 6 \mathrm{~cm}$. It was noted to be hard and fixed to the underlying soft tissue structures and led to a resultant right sided deviation of his trachea. His cervical lymph nodes were not palpable across all subgroups.

He was further investigated with an X-ray of his right arm which revealed lytic lesions. A subsequent 


\section{Cureus}

computed tomography (CT) scan of his right upper extremity (Figure 1) showed the existence of an aggressive neoplastic process in the proximal diaphysis of the humerus that had invaded the intramedullary canal, leading to the expansion of the cortex with a resultant erosion which culminated to a complete pathological fracture.

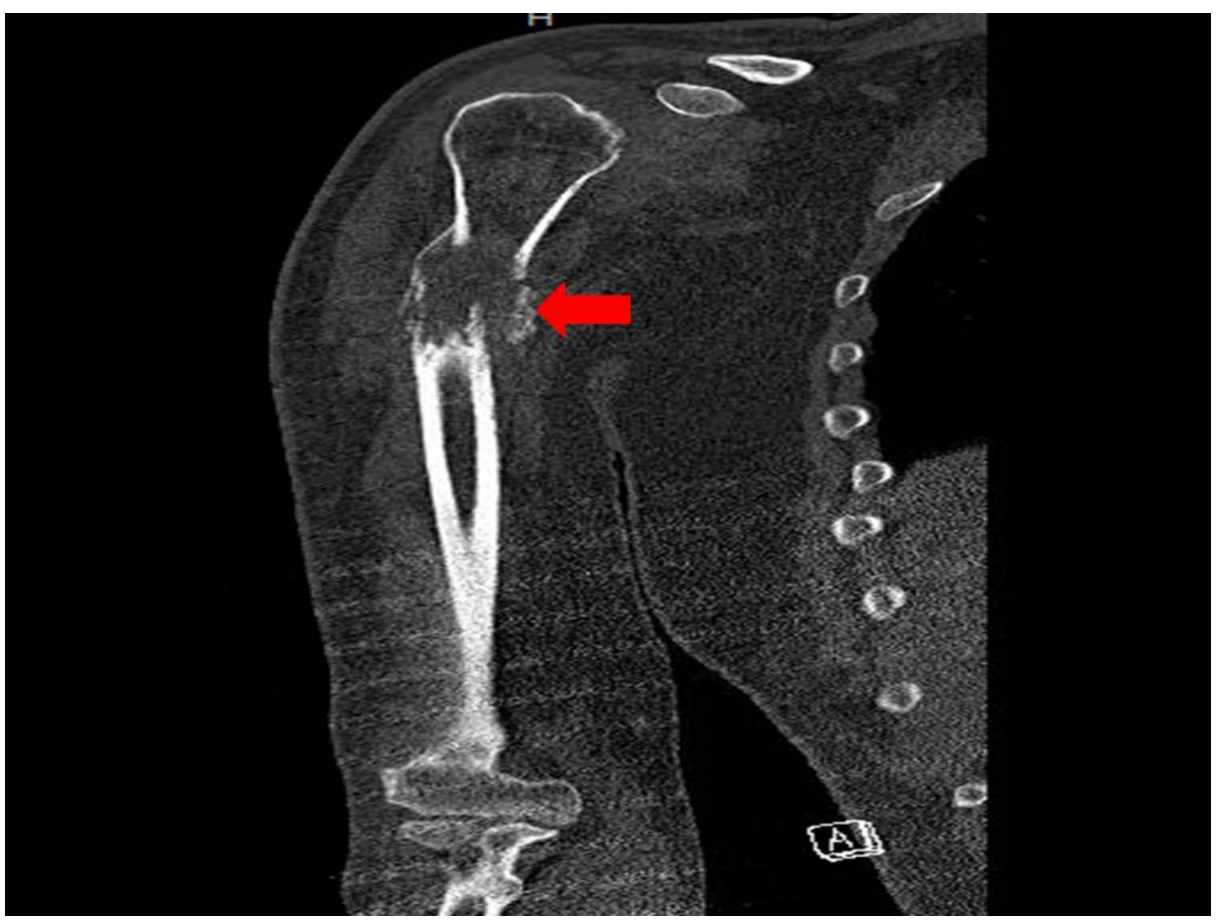

FIGURE 1: Computed tomography scan of the right arm showing a mass lesion (red arrow) in the proximal diaphysis of the humerus, invading the intramedullary canal and extending beyond the boundaries of the humerus.

A CT scan of the neck (Figure 2) showed a necrotic mass in the left thyroid gland that measured $6.7 \mathrm{~cm} \times 8.4$ $\mathrm{cm}$ and extended into the anterior mediastinum leading to the compression of vital vascular structures such as the left carotid artery and the left internal jugular vein.

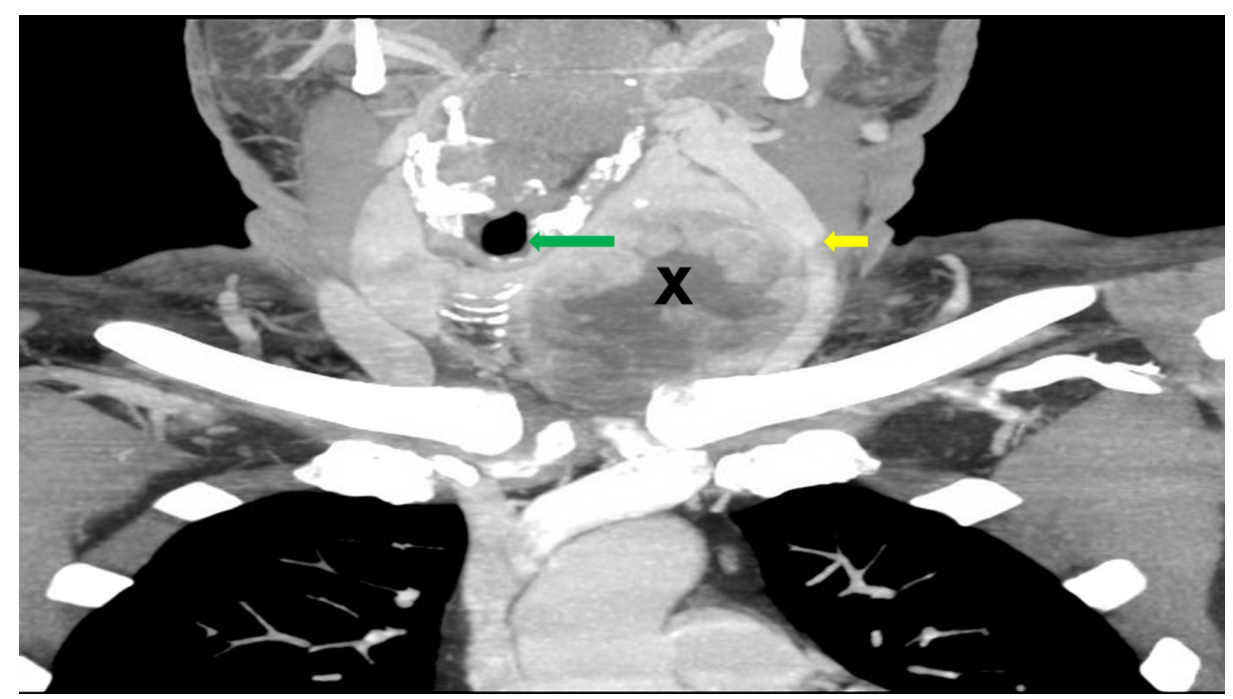

FIGURE 2: Computed tomography scan of the neck showing a necrotic thyroid mass (labeled $\mathrm{X}$ ) on the left side, extending into the anterior mediastinum, and compressing the surrounding structures including the internal jugular vein (yellow arrow). Also visible is the trachea 
The tumor had well-defined margins but was not associated with cervical lymphadenopathy. In order to establish a tissue diagnosis, the patient was subjected to a fine needle biopsy (FNA) and a CT guided biopsy of the mass, which revealed a metastatic papillary carcinoma of the thyroid gland. Immunohistochemistry further revealed it to be positive for Thyroid Transcription Factor 1 (TTF-1), Vimentin and Cytokeratin 7 (CK7) and negative for Napsin A, carcinoembryonic antigen (CEA), prostate-specific acid phosphatase (PSAP), prostate-specific antigen (PSA), Cytokeratin 20 (CK20) and CDX2 tumor markers. The patient was further analyzed for a metastatic disease via a bone scintigraphy (Figure 3) which showed an increased uptake in the proximal humerus and the apex of the skull with an extradural effect. During the bone scan workup, there was an evident increase in the size of the swelling in his frontal bone.

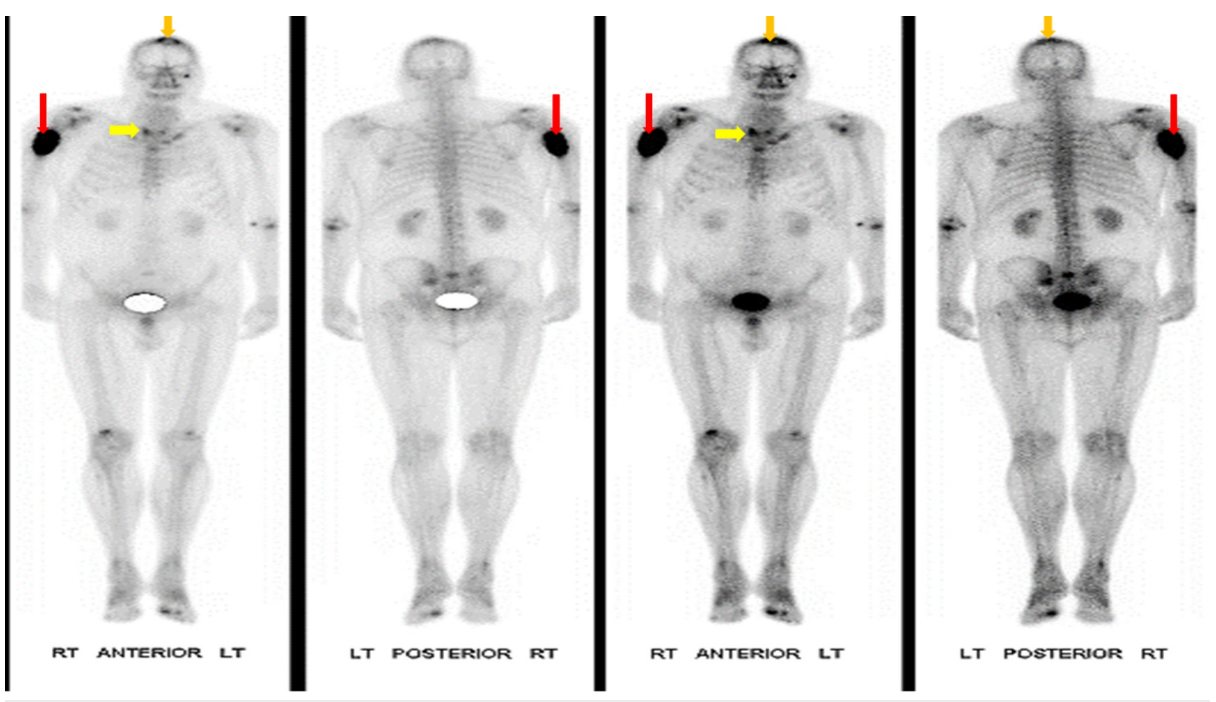

FIGURE 3: Bone scintigraphy of the patient, showing an increased uptake in the right proximal humerus (red arrows) as well as the apex of the skull (orange arrows). There is also an increased uptake in thyroid gland (Yellow arrows).

This mass was further investigated with a magnetic resonance imaging (MRI) scan of the head (Figure 4) which revealed an enhancing calvarial mass with an extension into the subcutaneous tissue. There was also an incursion into the inner table of the calvarium with a possible invasion of the dura at the vertex. This was accompanied by a $6 \mathrm{~cm} \times 4 \mathrm{~cm} \times 4 \mathrm{~cm}$ mass that presented as a probable invasive meningioma or a metastatic lesion. The invasiveness of this mass was further assessed via a conventional cerebral angiogram which confirmed the suspicion that the mass had raided the superior sagittal sinus. 


\section{Cureus}

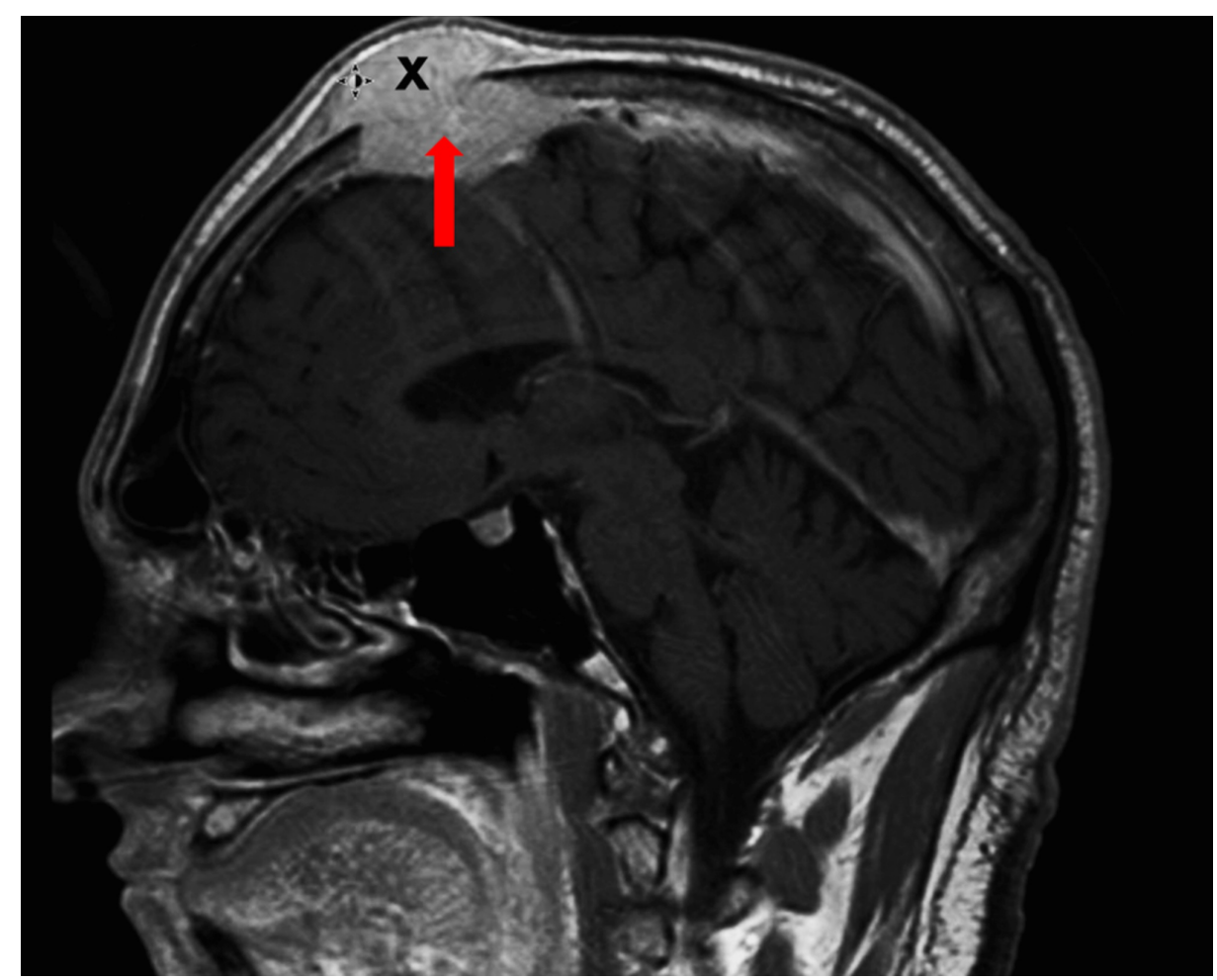

FIGURE 4: Magnetic resonance imaging of the head showing an enhancing calvarial mass (marked $X$ ) invading into the subcutaneous tissue (red arrow). Also visible is the involvement of the inner table of the calvarium, and invasion of the dura mater by the mass at the vertex.

As illustrated, the patient had a myriad of clinical issues which warranted prompt surgical intervention. He first underwent a total thyroidectomy. The histological evaluation suggested that the tumor was a follicular variant of a papillary carcinoma, measuring $10 \mathrm{~cm}$ x $6.5 \mathrm{~cm}$ x $6 \mathrm{~cm}$ with a lack of lymphovascular invasion. Three days following the thyroidectomy, the patient underwent a bi-frontal craniectomy which included the resection of the superior sagittal sinus and part of falx cerebri along with the tumor, which measured $5.8 \mathrm{~cm}$ $\mathrm{x} 6 \mathrm{~cm}$ x $4 \mathrm{~cm}$. The histological evaluation revealed a metastatic papillary thyroid carcinoma involving the dura with extensive lymphovascular invasion. The tumor cells were morphologically similar to a follicular variant of a papillary thyroid carcinoma which is a very rare clinical find. The tumor cells were negative for CK20 and CDX2 and positive for CK7, TTF1, and PAX8 markers. These findings supported the morphological impression and the above diagnosis. Cranioplasty was performed one week after the craniectomy.

His initial chief clinical complaint of a right humeral lesion was eventually addressed. The mass was excised and a reconstruction was performed with a humeral bone allograft and stabilized with a periarticular humerus plate. Following a recovery from this array of surgical interventions, the patient was started on radiotherapy. The patient is scheduled for an upcoming magnetic resonance imaging (MRI) scan and an I131 whole body scan.

\section{Discussion}

Thyroid cancer is the most common endocrinal cancer in the world, with a rising global incidence over the last three decades [4]. Fortunately, the five-year survival rate continues to improve over the same time period and is currently perched at a strong $97.8 \%$. This can be attributed to the fact that $70 \%$ of the cases are now diagnosed at the initial stage [5].

A frequent presentation of thyroid cancer is a neck mass which could be asymptomatic or present with troublesome features. The presence of symptoms such as dyspnea, dysphagia or hoarseness of the voice usually indicates that the tumor is aggressive and is involving the recurrent laryngeal nerve. Other symptoms such as a cough, dyspnea, and stridor suggest a tracheal impediment, secondary to the mass effect of a locally invasive tumor. Such findings accentuate the need for a thorough patient history and a comprehensive physical examination [6].

Approximately $90 \%$ of the thyroid neoplasms are differentiated thyroid cancers (DTC). This term incorporates both papillary and follicular variants [7]. Only a small proportion (2\%-13\%) of the patients 
afflicted with DTC develop bony metastasis; unfortunately, this decreases the survival rate by more than $60 \%$. The axial skeleton is the primary site of metastatic spread, with the most common sites of metastases being the spine (34.6\%), the pelvis (25.5\%), sternum and ribs (18.3\%), extremities (10.2\%), shoulder girdle (5.4\%), and the craniomaxillofacial bones (5.4\%) [8]. The metastatic incursion of the skull develops in $2.5 \%$ $5.8 \%$ of the cases and mostly affects the base and the tissues that dwell within, such as the sella turcica, pituitary gland and vascular structures such as the cavernous and sphenoid sinuses [9].

The histological description of a DTC plays a pivotal role in determining patient outcomes in terms of metastatic spread and their survival. Various studies have shown that histology is the single most important predictor of mortality in patients with distant metastasis, in comparison to other variables such as age, the degree of tumor infiltration, the extent of lymphovascular invasion and the size of the tumor [10]. PTC is the most common histological variant of a DTC and accounts for $74 \%-80 \%$ of all its cases [3]. PTCs are mostly associated with a slow progression and regional spread to the cervical lymph nodes. They tend to carry a favorable outcome, while patients having a metastatic disease process are the usual exception [1]. A distant metastatic distribution in the setting of a PTC occurs in approximately $10 \%$ of the patients, with the lung and bone being the most commonly affected sites [2]. While the occurrence itself is rare, bony metastases from a PTC tend to be multiple and mostly afflict the ribs, vertebrae, and sternum [11]. The incidence of FTC is less common when compared to a PTC, but it is still more likely to spread to the bones [12]. Our patient presented with a follicular variant of a papillary thyroid cancer (FV-PTC) which amalgamates the histological and clinical presentation of both subvariants of a DTC, however, FV-PTC has more resemblance with a follicular carcinoma [10].

As already stated, a thyroid malignancy usually presents as a lone neck mass. It is rare for thyroid cancers to first come to attention with symptoms of a metastatic disease [13]. Our patient demonstrated a welldifferentiated and encapsulated FV-PTC with distant metastasis as his initial presentation, and we wish to highlight the rarity of such a clinical exhibition. Calvarial metastases are uncommon, and rarely breach the inner table to involve the dura mater. Making a diagnosis can be especially challenging because of the exceptionally rare occurrence of this clinical entity which may lead some clinicians to erroneously diagnose it as another lesion, such as a meningioma. Metastatic lesions to the skull are mostly asymptomatic masses that usually colonize to the occipital region. However, our case showed the involvement of the vertex which is another unusual clinical find. Per our review of the literature, a pathological fracture of the humerus, as in our case-report, is also very uncommon with only one other article reporting a similar finding due to a DTC with follicular metastatic cancer [14].

Diagnosing such a clinical entity is based on maintaining clinical suspicion and obtaining consequent radiological evidence. Imaging with a CT scan or MRI is essential for detecting the lesion, localizing the primary pathology as well as assessing the extension of the disease process. Lesions infiltrating into the bones may appear osteolytic on an X-ray and/or a CT scan. They usually have a very prominent vascular component which is analogous to the findings in our patient. These tumors may have a dense blood supply and an angiography may be necessary to assess the vascularity and guide resection [3]. We followed the conventional approach for the management of a metastatic PTC which includes a total thyroidectomy, along with the removal of any resectable metastatic lesions followed by radioactive iodine (RAI) and/or external beam radiation at the sites of metastases. For cases where the metastatic disease is found to be resistant to conventional therapies, some clinical trials show promise with the use of anti-angiogenic tyrosine kinase inhibitors (TKIs) such as Sorafenib [15-17]. Dismayingly, this all-encompassing treatment plan yields unsatisfactory outcomes because the prognosis for such patients continues to be dissatisfactory, with a 10year survival rate of only $27 \%$ [18].

We conducted a literature review of all the cases between 1986 and 2018 using PubMed. To date, 21 cases of PTC with skull metastasis have been reported (Table 1). The mean age of these patients was 60.1 years, ranging from 25 to 76 years. A female predominance (71\%) was observed in patients presenting with this disease process. Per our review, eight of the 21 cases had the follicular variant of PTC which was similar to the diagnosis in our case. We noted that dural involvement with skull metastases was only found in nine previous cases, with our case as the tenth. This reiterates the rarity of such a demonstration. Half of the patients underwent a surgical resection for their bone metastases while others were subjected to different treatment modalities which included RAI, external beam irradiation via intensity-modulated radiotherapy (IMRT) and radiotherapy. Patient demise was reported in two of these cases while the remaining patients have had a favorable clinical outcome to date.

\begin{tabular}{|c|c|c|c|c|c|c|c|c|}
\hline PUBLICATION & AGE & SEX & CLINICAL PRESENTATION & $\begin{array}{l}\text { MICROSCOPIC } \\
\text { FEATURES }\end{array}$ & SITE OF METS & $\begin{array}{l}\text { DURAL } \\
\text { INVOLVEMENT }\end{array}$ & TREATMENT & OUTCOME \\
\hline Nigam [3] & 48 & $\mathrm{~F}$ & $\begin{array}{l}\text { Painless swelling on the occipitoparietal } \\
\text { region of the scalp }\end{array}$ & PTC & $\begin{array}{l}\text { Occipitoparietal region with } \\
\text { intracranial extension }\end{array}$ & Yes & $\begin{array}{l}\text { Chemotherapy, } \\
\text { Radiotherapy }\end{array}$ & Uneventful \\
\hline Li [9] & 61 & $\mathrm{~F}$ & Asymptomatic & PTC & Frontal and Parietal skull & Yes & Surgery, RAI & Uneventful \\
\hline Tunio [19] & 74 & $\mathrm{~F}$ & Left upper neck pain, CN XII palsy. & rive ralicen & Left occipital conayle and lert & No & IMRT & Uneventful \\
\hline
\end{tabular}




\section{Cureus}

\begin{tabular}{|c|c|c|c|c|c|c|c|c|}
\hline & & & & variant & side of clivus & & & \\
\hline Tunio [19] & 67 & $\mathrm{~F}$ & $\begin{array}{l}\text { Headache, diplopia, facial weakness, CN } \\
\text { II, III and VI palsy. }\end{array}$ & $\begin{array}{l}\text { PTC, Insular } \\
\text { variant }\end{array}$ & $\begin{array}{l}\text { Right cavernous sinus } \\
\text { extending to the pituitary } \\
\text { fossa and clivus }\end{array}$ & Inconclusive & IMRT & Uneventful \\
\hline Tunio [19] & 65 & M & $\begin{array}{l}\text { Headache, dysphagia, hoarseness, } \\
\text { dysarthria, hearing impairment, CN IX, X, } \\
\text { XI, XII palsy. }\end{array}$ & $\begin{array}{l}\text { PTC, Follicular } \\
\text { variant }\end{array}$ & $\begin{array}{l}\text { Left temporal bone with } \\
\text { intracranial extension }\end{array}$ & Inconclusive & Surgery, IMRT & Uneventful \\
\hline Jouhar [20] & 42 & $\mathrm{~F}$ & Lower back pain with fever and sweating & $\begin{array}{l}\text { PTC, Follicular } \\
\text { variant }\end{array}$ & Parietal skull, Sacrum & No & $\begin{array}{l}\text { Palliative } \\
\text { management }\end{array}$ & Unknown \\
\hline Al-Qahtani [21] & 65 & $\mathrm{~F}$ & Painful lump over the occipital region & $\begin{array}{l}\text { PTC, Follicular } \\
\text { variant }\end{array}$ & $\begin{array}{l}\text { Left occipital bone with } \\
\text { intracranial invasion }\end{array}$ & Yes & $\begin{array}{l}\text { IMRT, } \\
\text { Sorafenib }\end{array}$ & Uneventful \\
\hline Sisson [22] & 65 & M & Posterior head swelling & $\begin{array}{l}\text { PTC, Follicular } \\
\text { variant }\end{array}$ & Posterior skull & Yes & $\begin{array}{l}\text { RAl, Thyroxine } \\
\text { therapy }\end{array}$ & Uneventful \\
\hline Pyo [23] & 25 & M & Asymptomatic & $\begin{array}{l}\text { PTC, Follicular } \\
\text { variant }\end{array}$ & $\begin{array}{l}\text { Frontal bone and the left 5th } \\
\text { rib }\end{array}$ & No & $\begin{array}{l}\text { Surgery, RAl, } \\
\text { Palliative } \\
\text { radiation }\end{array}$ & Uneventful \\
\hline Freeman [24] & 50 & M & Facial pain, proptosis, Horner syndrome. & PTC & $\begin{array}{l}\text { Sphenoid/Ethmoid sinus, skull } \\
\text { base }\end{array}$ & Yes & IMRT, RAI & Uneventful \\
\hline Kung [25] & 55 & $\mathrm{~F}$ & Mass in right occipital region & PTC & Occipital bone & No & $\begin{array}{l}\text { Surgery, } \\
\text { Radiotherapy }\end{array}$ & Uneventful \\
\hline Feng [26] & 62 & $\mathrm{~F}$ & Headache, painless mass in forehead & PTC & Frontal bone & Yes & Surgery & Uneventful \\
\hline Kusunoki [27] & 70 & $\mathrm{~F}$ & Left Parietal mass & PTC & Parietal bone & No & Surgery & unknown \\
\hline Hugh [28] & 64 & $\mathrm{~F}$ & Mass in lateral skull base & $\begin{array}{l}\text { PTC, Follicular } \\
\text { variant }\end{array}$ & $\begin{array}{l}\text { Occipital bone, Petrous bone, } \\
\text { cerebellopontine angle }\end{array}$ & Inconclusive & Surgery, IMRT & Uneventful \\
\hline Kutluhan [29] & 61 & M & $\begin{array}{l}\text { Left postauricular swelling, Multiple CN } \\
\text { palsies }\end{array}$ & PTC & Temporoccipital region & No & $\begin{array}{l}\text { RAl, } \\
\text { Radiotherapy }\end{array}$ & Unknown \\
\hline Houra [30] & 76 & $\mathrm{~F}$ & $\begin{array}{l}\text { Headache, confusion, Painful mass on } \\
\text { right side of forehead }\end{array}$ & PTC & $\begin{array}{l}\text { Frontal bone extending } \\
\text { intracranially }\end{array}$ & Yes & Surgery & Uneventful \\
\hline Miyawaki [31] & 55 & $\mathrm{~F}$ & Asymptomatic neck mass & $\begin{array}{l}\text { PTC, Follicular } \\
\text { variant }\end{array}$ & Parietal bone, Lung & No & $\begin{array}{l}\text { Surgery, } \\
\text { Radiotherapy }\end{array}$ & Uneventful \\
\hline $\begin{array}{l}\text { Mostarchid } \\
{[32]}\end{array}$ & 50 & $\mathrm{~F}$ & Headache, torticollis, scalp mass & PTC & $\begin{array}{l}\text { Temporoparietal occipital } \\
\text { region }\end{array}$ & Yes & $\begin{array}{l}\text { Refused } \\
\text { treatment }\end{array}$ & Died \\
\hline Hashiba [33] & 74 & $\mathrm{~F}$ & $\begin{array}{l}\text { Painless mass on the forehead, café au } \\
\text { lait spots on the body }\end{array}$ & PTC & Frontal bone & Yes & Surgery, RAI & Uneventful \\
\hline Yan [34] & 73 & $\mathrm{M}$ & Headache, diplopia, visual impairment & PTC & Skull base, Clivus & No & Surgery & Died \\
\hline Cardenas [35] & 59 & $\mathrm{~F}$ & Asymptomatic & $\begin{array}{l}\text { PTC, Follicular } \\
\text { variant }\end{array}$ & $\begin{array}{l}\text { Occipital bone, Ribs, sacrum, } \\
\text { ischium, femoral neck }\end{array}$ & No & RAI & Uneventful \\
\hline Our case & 54 & $\mathrm{M}$ & $\begin{array}{l}\text { Painless frontal bone mass, right arm } \\
\text { pain. }\end{array}$ & $\begin{array}{l}\text { PTC, Follicular } \\
\text { variant }\end{array}$ & $\begin{array}{l}\text { Frontal bone and diaphysis of } \\
\text { Humerus. }\end{array}$ & Yes & $\begin{array}{l}\text { Surgery, } \\
\text { Radiotherapy }\end{array}$ & Uneventful \\
\hline
\end{tabular}

\section{TABLE 1: Literature review of all the cases between 1986 and 2018 of PTC with skull metastasis,}

utilizing PubMed.

M: Male; F: Female; PTC: Papillary thyroid carcinoma; RAI: Radioactive iodine; IMRT: External beam irradiation via intensity modulated radiotherapy.

\section{Conclusions}

PTC with distant metastases markedly worsens the patient's prognosis. It is rarely associated with a metastatic spread to the skull. Diagnosing such a rare clinical entity is a challenging task and is made possible via a high clinical suspicion and resultant radiographic evidence. Metastatic growth usually presents as an asymptomatic skull mass which is mostly located in the occipital region, but a few cases of 
frontal involvement have been reported. The conventional therapy for a metastatic PTC includes total thyroidectomy, the removal of resectable metastatic lesions, RAI and/or external beam radiation at the sites of metastases. Tyrosine kinase inhibitors have proven beneficial for refractory cases. This case and our literature review illustrate that skull metastases should be considered in the clinical course of PTC because early diagnosis leads to prompt treatment which can improve patient survival.

\section{Additional Information \\ Disclosures}

Conflicts of interest: In compliance with the ICMJE uniform disclosure form, all authors declare the following: Payment/services info: All authors have declared that no financial support was received from any organization for the submitted work. Financial relationships: All authors have declared that they have no financial relationships at present or within the previous three years with any organizations that might have an interest in the submitted work. Other relationships: All authors have declared that there are no other relationships or activities that could appear to have influenced the submitted work.

\section{References}

1. Cobin RH, Gharib H, Bergman DA, et al.: AACE/AAES medical/surgical guidelines for clinical practice: management of thyroid carcinoma. Endocr Pract. 2001, 7:202-220. 10.4158/EP.7.3.202

2. Schlumberger M, Tubiana M, De Vathaire F, et al.: Long-term results of treatment of 283 patients with lung and bone metastases from differentiated thyroid carcinoma. J Clin Endocrinol Metab. 1986, 63:960-967. 10.1210/jcem-63-4-960

3. Nigam A, Singh AK, Singh SK, Singh N: Skull metastasis in papillary carcinoma of thyroid: a case report . World J Radiol. 2012, 4:286-290. 10.4329/wjr.v4.i6.286

4. Pellegriti G, Frasca F, Regalbuto C, Squatrito S, Vigneri R: Worldwide increasing incidence of thyroid cancer: update on epidemiology and risk factors. J Cancer Epidemiol. 2013, 2013:965212. 10.1155/2013/965212

5. Nguyen QT, Lee EJ, Huang MG, Park YI, Khullar A, Plodkowski RA: Diagnosis and treatment of patients with thyroid cancer. Am Health Drug Benefits. 2015, 8:30-40.

6. Parsa AA, Gharib H: Thyroid nodules. Contemporary Endocrinology. Gharib H (ed): Humana Press, Cham; 2018. 231. 10.1007/978-3-319-59474-3

7. Sherman SI: Thyroid carcinoma. Lancet. 2003, 361:501-511. 10.1016/S0140-6736(03)12488-9

8. Osorio M, Moubayed SP, Su H, Urken ML: Systematic review of site distribution of bone metastases in differentiated thyroid cancer. Head Neck. 2017, 39:812-818. 10.1002/hed.24655

9. Li X, Zhao G, Zhang Y, et al.: Skull metastasis revealing a papillary thyroid carcinoma . Chin J Cancer Res. 2013, 25:603-607. 10.3978/j.issn.1000-9604.2013.09.05

10. Yu XM, Schneider DF, Leverson G, Chen H, Sippel RS: Follicular variant of papillary thyroid carcinoma is a unique clinical entity: a population-based study of 10,740 cases. Thyroid. 2013, 23:1263-1268. 10.1089/thy.2012.0453

11. Zettinig G, Fueger BJ, Passler C, Kaserer K, Pirich C, Dudczak R, Niederle B: Long-term follow-up of patients with bone metastases from differentiated thyroid carcinoma - surgery or conventional therapy?. Clin Endocrinol. 2002, 56:377-382. 10.1046/j.1365-2265.2002.01482.x

12. Proye CA, Dromer DH, Carnaille BM, et al.: Is it still worthwhile to treat bone metastases from differentiated thyroid carcinoma with radioactive iodine?. World J Surg. 1992, 16:640-645. 10.1007\%2FBF02067343

13. Muresan MM, Olivier P, Leclere J, et al.: Bone metastases from differentiated thyroid carcinoma . Endocr Relat Cancer. 2008, 15:37-49. 10.1677/ERC-07-0229

14. Yang W, Cho W, Das S, Conboy P: Follicular thyroid carcinoma presenting with pathological fracture of the humerus at initial diagnosis. J Surg Case Rep. 2017, 2017: 10.1093/jscr/rjx002

15. Cooper DS, Doherty GM, Haugen BR, et al.: Revised American Thyroid Association management guidelines for patients with thyroid nodules and differentiated thyroid cancer. Thyroid. 2009, 19:1167-1214. 10.1089/thy.2009.0110

16. Gupta-Abramson V, Troxel AB, Nellore A, et al.: Phase II trial of sorafenib in advanced thyroid cancer . J Clin Oncol. 2008, 26:4714-4719. 10.1200/JCO.2008.16.3279

17. Hoftijzer H, Heemstra KA, Morreau H, et al.: Beneficial effects of sorafenib on tumor progression, but not on radioiodine uptake, in patients with differentiated thyroid carcinoma. Eur J Endocrinol. 2009, 161:923-931. 10.1530/EJE-09-0702

18. Wada N, Sugino K, Mimura T, et al.: Treatment strategy of papillary thyroid carcinoma in children and adolescents: clinical significance of the initial nodal manifestation. Ann Surg Oncol. 2009, 16:3442-3449. 10.1245/s10434-009-0673-4

19. Tunio MA, Al Asiri M, Al-Qahtani KH, Al-Dandan S, Riaz K, Bayoumi Y: Skull base metastasis from papillary thyroid carcinoma: a report of three cases. Int Med Case Rep J. 2015, 8:127-131. 10.2147/IMCRJ.S82792

20. Jouhar FS, Quadri A, Afandi B, Al Rawi S: Occult papillary thyroid carcinoma metastasis to the sacrum and the skull: an unusual presentation. Case Rep Med. 2014, 2014:516549. 10.1155/2014/516549

21. Al-Qahtani KH, Tunio MA, Al Asiri M: Calvarium and dura mater as delayed sites of distant metastasis from papillary thyroid carcinoma. Int Med Case Rep J. 2015, 8:251-254. 10.2147/IMCRJ.S86183

22. Sisson JC, Dewaraja YK, Wizauer EJ, Giordano TJ, Avram AM: Thyroid carcinoma metastasis to skull with infringement of brain: treatment with radioiodine. Thyroid. 2009, 19:297-303. 10.1089/thy.2008.0426

23. Pyo JY, Kim J, Choi SE, et al.: Extremely well-differentiated papillary thyroid carcinoma resembling adenomatous hyperplasia can metastasize to the skull: a case report. Yonsei Med J. 2017, 58:255-258. 10.3349/ymj.2017.58.1.255

24. Freeman JL, Gershon A, Liavaag PG, Walfish PG : Papillary thyroid carcinoma metastasizing to the sphenoid-ethmoid sinuses and skull base. Thyroid. 1996, 6:59-61. 10.1089/thy.1996.6.59 


\section{Cureus}

25. Kung VW, Wong GK, Zhu XL, Ying SY, Ahuja AT, Poon WS, Ng HK: Solitary skull metastasis of thyroid papillary carcinoma. ANZ J Surg. 2007, 77:1030-1031. 10.1111/j.1445-2197.2007.04311.x

26. Feng D, Rhatigan R, Shuja S, Wolfson D, Makary R, Koch K, Masood S: Papillary thyroid carcinoma with metastasis to the frontal skull. Diagn Cytopathol. 2009, 37:522-526. 10.1002/dc.21070

27. Kusunoki T, Urano K, Saito K, Murata K: A case of skull metastasis from thyroid papillary carcinoma . Thyroid. 2003, 13:889-890. 10.1089/105072503322401113

28. Hugh SC, Enepekides D, Wong J, Yeung R, Lin VYW: Metastasis of follicular variant of papillary thyroid carcinoma masquerading as primary temporal bone tumour. J Laryngol Otol. 2011, 125:528-532. 10.1017/S0022215110002926

29. Kutluhan A, Yalciner G, Bozdemir K, Özdemir E, Tarlak B, Bilgen AS: Papillary thyroid carcinoma with metastasis to the temporooccipital skull: a case report. Kulak Burun Bogaz Ihtis Derg. 2012, 22:160-163. 10.5606/kbbihtisas.2012.030

30. Houra K, Vucic M, Cupic H, Kovac D, Cerina V: Osteolytic skull metastasis with dural involvement from a papillary thyroid carcinoma. Coll Antropol. 2011, 35:919-922.

31. Miyawaki S, Yamazaki R, Harada T, et al.: Skull metastasis of thyroid papillary carcinoma . J Clin Neurosci. 2007, 14:481-484. 10.1016/j.jocn.2006.01.032

32. Mostarchid BE, Akhaddar A, Boucetta M: Giant skull and brain metastasis from a neglected thyroid papillary carcinoma. Can J Neurol Sci. 2010, 37:515-516. 10.1017/S0317167100010568

33. Hashiba T, Maruno M, Fujimoto Y, et al.: Skull metastasis from papillary thyroid carcinoma accompanied by neurofibromatosis type 1 and pheochromocytoma: report of a case. Brain Tumor Pathol. 2006, 23:97-100. 10.1007/s10014-006-0203-Z

34. Yan B, Liu DG, Lu HL, Zhang QH: Images for diagnosis. Papillary thyroid microcarcinoma presenting as skull base metastasis. Chin Med J (Engl). 2010, 123:2750-2752.

35. Cardenas MG, Kini S, Wisgerhof M: Two patients with highly aggressive macrofollicular variant of papillary thyroid carcinoma. Thyroid. 2009, 19:413-416. 10.1089/thy.2008.0178 